\title{
Intravenous to oral antimicrobial stepdown therapy: Improving the quality of care and reducing costs
}

JOHN M CONLY MD, DONALD E LOW MD

I NFECTIOUS DISEASES CONTINUE TO PLAGUE MANKIND AND the treatment of infections continues to consume a considerable proportion of healthcare resources. From an international viewpoint, the use of antibacterial agents to treat infections accounts for between 3 and $25 \%$ of all prescriptions and 6 and $21 \%$ of the market value of the drugs (1). A recent European five-country survey of the management of infections and the use of antibiotic therapy in acute care hospitals revealed that lower respiratory tract, urinary tract, and intra-abdominal infections accounted for $75 \%$ of all infections, but marked variation in the route of administration was observed (2). In Italy $80 \%$ of all administration was parenteral whereas in the United Kingdom 60\% of the administrations were on an oral basis. In the United States there is also considerable variation in the routes of administration of antimicrobial agents. Respiratory tract infections are the most commonly encountered infections in the United States (3) and in a national health survey conducted in the 1980 s they were estimated to account for over 200 million infection episodes per annum (4). Indeed, the use of antibiotics for the treatment of infections of the respiratory tract in hospitalized patients accounts for approximately one-third of all prescriptions for these patients $(5,6)$. Overall, the estimated antimicrobial costs were approximately
US\$23 million per year. Overall, antibacterial agents account for 25 to $50 \%$ of the total drug budget of most US hospitals (7). In Canada antibiotics continue to account for a major portion of drug expenditures and revenues from patented antibiotics accounted for $\$ 307$ million in sales according to the 1991 report of the Patented Medicine Prices Review Board (8).

Rapidly escalating antimicrobial costs in the face of increasingly limited resources have led to greater emphasis on the economic aspects of antibiotic therapy in recent years. Coupled with the trends towards reducing the costs of antibiotic treatment has been the increasing availability of newer oral antimicrobials with improved potency, pharmacokinetic parameters and bioavailability. In addition, research into the pharmacodynamics of the 'bug-drug' interaction which can be viewed as the integration of pharmacokinetics (drug levels), minimal inhibitory concentration (susceptibility), post-antibiotic effect, effective regrowth time, and in vivo behaviour of the antimicrobial in the host, has created a new understanding of the optimum dosing of antimicrobials (9-11).

It is against this background of the juxtaposition of the need to reduce antimicrobial costs but at the same time to improve the quality care that we find the concept of intravenous to oral conversion of antimicrobials.

Section of Infectious Diseases, Department of Medicine, The Toronto Hospital, and Department of Microbiology, Mount Sinai and Princess Margaret Hospitals, Toronto, Ontario

Correspondence: Dr John M Conly, Section of Infectious Diseases, Department of Medicine, The Toronto Hospital, NU 13-117. 585 University Avenue, Toronto, Ontario M5G 2C4, telephone 416-340-4858, Fax 416-340-5047, e-mail jconly@torhosp.toronto.on.ca 


\section{THE CONCEPT OF INTRAVENOUS TO ORAL ANTIMICROBIAL CONVERSION OR 'STEPDOWN'}

Conversion programs for antimicrobials may be considered in the context of dosage, interval and route or any combination thereof. Although conversions from higher to lower dosages and from shorter to longer intervals have been used for many years, early conversion from intravenous to oral therapy in the hospitalized patient has never received much emphasis. The introduction of a formal program or mechanism to convert from intravenous to oral therapy, also referred to as 'switch' therapy (12) or 'stepdown' therapy (13), is not novel but if used to its full extent represents a unique and exciting opportunity to reduce costs significantly while improving the quality of patient care.

Although some clinicians are hesitant to initiate early transition to oral anti-infective therapy or to change the regimen of a patient who is demonstrating signs of improvement, there is increasing evidence to support the early use of oral agents in the treatment of several infectious diseases $(14,15)$. Several studies have assessed the efficacy of oral antimicrobial therapy in various infections including respiratory tract infections $(16,17)$, skin and soft tissue infections $(18,19)$ and bone and joint infections (20-22) and have provided considerable evidence to suggest the use of oral agents is both safe and efficacious. For many years our pediatric colleagues have treated children with acute osteomyelitis with oral agents after an initial (usually five to seven days) response to parenteral therapy, and gonococcal septic arthritis is often treated with oral therapy alone or after a brief course of parenteral therapy $(23,24)$. The treatment of intra-abdominal infections or anaerobic brain abscesses with oral as opposed to intravenous metronidazole has also been reported (25). Louie (26) has recently reviewed a number of clinical trials comparing intravenous with oral therapy. With the exception of patients with infections in areas into which antibiotic penetration is poor (ie, meningitis and infective endocarditis) the majority of hospitalized patients do not require prolonged courses of parenteral therapy.

Additional supporting evidence for the use of oral antimicrobials earlier in the course of treatment for infectious diseases may be found by a careful analysis of the pharmacokinetics of many antimicrobials (26, 27). Several agents including metronidazole, clindamycin, amoxicillin, trimethoprim-sulphamethoxazole, ciprofloxacin, ofloxacin, doxycycline and cephalexin achieve high serum levels and excellent tissue penetration when given orally. The bioactivity of these agents suggests that they could be expected to achieve similar clinical results as intravenous preparations in patients with a normal absorptive capacity. Identification of patients for whom early conversion to oral therapy may be utilized must be individualized based upon the patient's clinical status, lack of evidence suggesting malabsorption and ability to take medications orally.

\section{ECONOMIC CONSIDERATIONS OF STEPDOWN THERAPY}

Several studies have considered the economic impact (13,28-30) of conversion therapy and these investigations suggest that significant cost savings may be achieved through a reduction in direct acquisition costs, the absence of a need for special supplies required for intravenous medications, the decrease in related pharmacy and nursing labour, and the ability to shorten length of stay. The relative ease of preparation, storage and administration of oral medications also makes this mode of administration more convenient as well as less expensive.

A pilot study at The Toronto Hospital (3) suggests that at least $40 \%$ of antibiotic days are eligible for early conversion to oral therapy. A similar survey of patients at Mount Sinai Hospital in Toronto revealed that $40 \%$ of patients receiving a third-generation cephalosporin were eligible for oral therapy after $72 \mathrm{~h}$ of intravenous therapy (3). An unexpected finding was that when patients on a general medical ward were assessed for suitability for conversion therapy after 72 h, 20\% no longer were felt to require antimicrobial therapy. Benefits to the patient also accrue, including the elimination of adverse events associated with intravenous therapy, increase of patient comfort and mobility if no intravenous therapy is required, and facilitation of a more active tangible role for the patient in his/her own treatment, not to mention the potential for early discharge. The implementation of a formalized early oral conversion program for hospitalized patients represents an ideal total quality management project and has a wide applicability for institutions across Canada. The potential for significant and meaningful cost savings in conjunction with improved quality of patient care on a national scale represents a unique opportunity which must not go unrecognized.

\section{THE CANADIAN INFECTIOUS DISEASE SOCIETY SATELLITE SYMPOSIUM ON CONVERSION THERAPY}

To facilitate the initiative for quality improvement and cost containment in the antimicrobial prescribing of anti-infectives, a symposium was held in conjunction with the Royal College of Physicians and Surgeons Meeting in September 1994. The idea for the symposium was discussed and agreed upon by the Executive of the Canadian Infectious Diseases Society (CIDS) in February 1994 and was one of the official symposia hosted by CIDS at the 1994 Royal College meeting. The symposium was truly national in scope both in its impact and through the participation of its speakers. The symposium did not have any admission fee and was open to other allied healthcare professionals who wished to attend.

The objectives for attendees who attended the symposium were: 
- to understand the concepts of conversion therapy

- to describe practical guidelines for choosing conversion therapy

- to estimate cost savings associated with the use of conversion therapy

- to discuss strategies for the implementation of a conversion program.

Support for the symposium was graciously provided by Health and Welfare Canada, National Health Research and Development Program, The Medical Research Council of Canada, and Bayer Inc. (Healthcare Division).

Dr Richard Quintiliani, Director of Infectious Diseases and Allergy-Immunology at the Hartford Hospital, University of Connecticut School of Medicine, provided a thorough overview of the basic concepts and economic aspects of conversion therapy and provided some of the background which has lead us to consider this concept in our everyday practice. Dr Peter Jewesson, Director of the Department of Pharmacy at Vancouver

\section{REFERENCES}

1. Col NF, O'Connor RW. Estimating worldwide current antibiotic usage: Report of Task Force 1. Rev Infect Dis 1987;9(Suppl 3):S232-43.

2. Hall GA. Antimicrobial practice. The management of infections and antibiotic therapy: A European survey. $J$ Antimicrob Chemother 1993:31:985-1000.

3. Garibaldi RA. Epidemiology of community-acquired respiratory tract infections in adults: Incidence, etiology, and impact. Am J Med 1985;78(Suppl 6B):32-7.

4. Dixon RE. Economic costs of respiratory tract infections in the United States. Am J Med 1985;78(Suppl 6B):45-51.

5. Davey PG, Malek MM, Parker SE. Pharmacoeconomics of antibacterial treatment. PharmacoEconomics 1992;1:409-37.

6. Townsend TR, Shapiro M, Rosner B, Kass EH. Use of antimicrobial drugs in general hospitals. I. Description of population and definition of methods. J Infect Dis 1979; 139:688-97.

7. Barriere SL. Cost containment of antimicrobial therapy. Drug Intelligence Clin Pharm 1985; 19:278-81.

8. Patented Medicine Prices Review Board, Fourth Annual Report. Ottawa, Ontario, Canada, 1991:1-63.

9. Vogelman B, Gundmundsson S, Legget J, et al. Correlation of antimicrobial pharmacokinetic parameters with efficacy in an animal model. J Infect Dis 1988;158:831-47.

10. Zhanel GG, Hoban DJ, Harding GKM. The postantibiotic effect: A review of in vitro and in vivo data. Ann Pharmacother 1991;25:153-63.

11. Ebert SC, Craig WA. Pharmacodynamic properties of antibiotics: Application to drug monitoring and dosage regimen design. Infect Control Hosp Epidemiol 1990; 11:319-26

12. Ramirez J, Srinath L, Akee S, Raff M. Switch therapy with oral cefixime after intravenous third generation cephalosporin for the treatment of community-acquired pneumonia. Abstract 1375, 18th International Congress of Chemotherapy, Stockholm, Sweden, 1993.

13. Frighetto L, Nickoloff D, Mortimusen SM, Marndani FS. Jewesson PJ. Intravenous to oral stepdown program: Four years of experience in a large teaching hospital. Ann Pharmacother 1992:26:1447-51.

14. Quintiliani R, Nightingale CH. Antimicrobials and therapeutic decision making: A historical perspective. Pharmacother 1991:11:65-135.

15. Briceland LL, Nightingale CH, Quintiliani R, Cooper BW, Smith KS. Antibiotic streamlining from combination therapy to monotherapy utilizing an interdisciplinary approach. Arch Intern Med 1988; 148:2019-22.

16. Ehrenkranz NJ, Nerenberg DE, Shultz JM, Slater KC. Intervention to discontinue parenteral antimicrobial therapy in patients hospitalized with pulmonary infections: Effect on
Hospital and Health Sciences Centre, provided attendees with an understanding of the pharmacokinetic principles for intravenous to oral conversion therapy and in his article provides a very useful grouping of anti-infective agents which may be used for stepdown. A compilation of experiences on stepdown therapy was then presented from individuals from institutions across Canada which have been active in the development of stepdown programs. Their contributions are presented as short vignettes and each represents a unique and valuable experience into approaches to stepdown therapy in Canadian hospitals. Contributions from Ottawa (Dr G Garber), Calgary (Dr T Louie), Hamilton (Dr L Mandell), Winnipeg (Dr L Nicolle), Halifax (Dr K Forward), Quebec (Dr M Bergeron) and Toronto (Dr D Low, Dr J Conly) provide an opportunity for readers to gain new insights from the lessons learned in the introduction of stepdown therapy in institutions from coast to coast.

shortening patient stay. Infect Control Hosp Epidemiol 1992; 13:21-32.

17. Wollschlager CM, Raoof S, Khan FA, et al. A controlled comparative study of ciprofloxacin versus ampicillin in treatment of bacterial respiratory tract infections. Am J Med 1987;82(Suppl 4A):164-8.

18. Kulhanjian K, Dunphy MG, Hamstra S, et al. Randomized comparative study of ampicillin/sulbactam vs ceftriaxone for treatment of soft tissue and skeletal infections in children. Paediatr Infect Dis J 1989;8:605-10.

19. Gentry LO, Rodriguez-Gomez G, Zeluff BJ, et al. A comparative evaluation of oral ofloxacin versus intravenous cefotaxime therapy for serious skin and skin structure infections. Am J Med 1989;87(Suppl 6C):31s-6s.

20. Kolyvas E, Ahronheim G, Marks MI, et al. Oral antibiotic therapy of skeletal infections in children. Paediatrics 1980;65:867-71.

21. Black J, Hunt TL, Godley PJ, et al. Oral antimicrobial therapy for adults with osteomyelitis or septic arthritis. J Infect Dis 1987:155:968-72.

22. Lesse AJ, Freer C, Salata RA, et al. Oral ciprofloxacin therapy for Gram-negative bacillary osteomyelitis. Am J Med 1987;82(Suppl 4A):247-52.

23. Nelson JD, Bucholz RW, Kusmiesz H, et al. Benefits and risks of sequential parenteral oral cephalosporin therapy for suppurative bone and joint infections. J Paediatr Orthop 1982;2:255-63.

24. Handsfield HH, Wiesneer PJ, Holmes KK. Treatment of gonococcal dermatitis - arthritis syndrome. Ann Intern Med 1976;84:661-7.

25. Wainer JF, Perkins RL, Cordero L. Metronidazole therapy of anaerobic bacteraemia, meningitis, and brain abscess. Arch Intern Med 1979;139:167-9.

26. Louie TJ. Intravenous to oral stepdown antibiotic therapy: Another cost-effective strategy in an era of shrinking healthcare dollars. Can J Infect Dis 1994:5(Suppl C):45C-50C.

27. Quintiliani R. Nightingale $\mathrm{CH}$. Antimicrobials and therapeutic decision-making: A historical perspective. Pharmacother 1991:11(Part 1):6S-13S.

28. Wang JC, Conly JM, Shafran SD. Appropriateness of metronidazole use in a teaching hospital. Am J Hosp Pharm 1989;46: 1385-9.

29. Jewesson P. Cost-effectiveness and value of an IV switch. PharmacoEconomics 1994;5(Suppl 2):20-6.

30. Rimmer D. Third generation cephalosporins in the parenteral to oral switch. PharmacoEconomics 1994;5(Suppl 2):27-33.

31. Zamin M. Pharmacy Resident Project. Development of route conversion program for antimicrobial therapy at The Toronto Hospital, 1994: 1-22.

32. McNaught A, Kozyrskyj A. Intravenous to oral stepdown program. Drug Info Bulletin, Mount Sinai Hospital, 1993:15. 


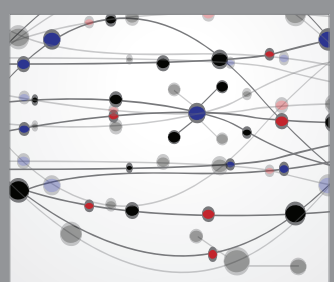

The Scientific World Journal
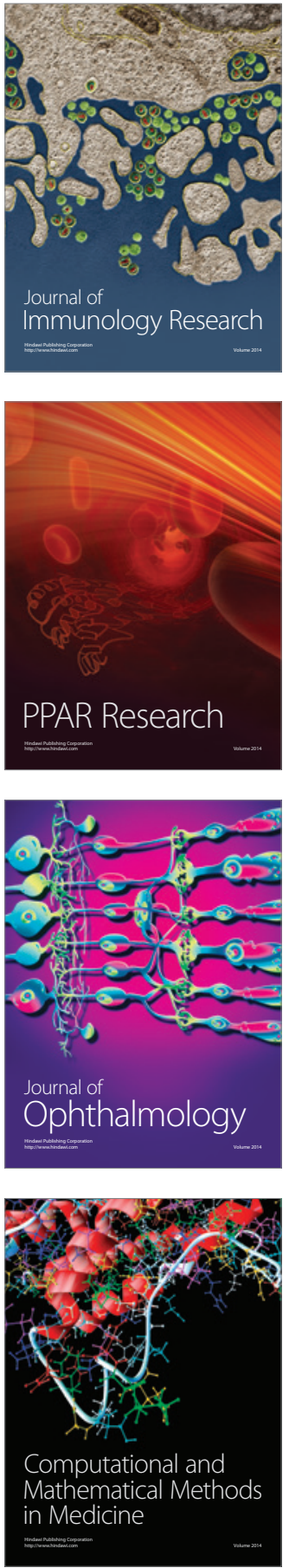

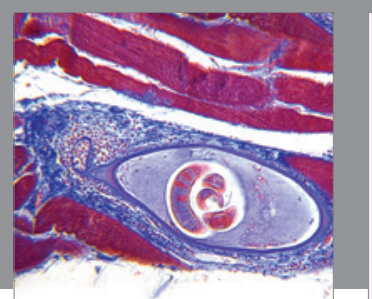

Gastroenterology Research and Practice

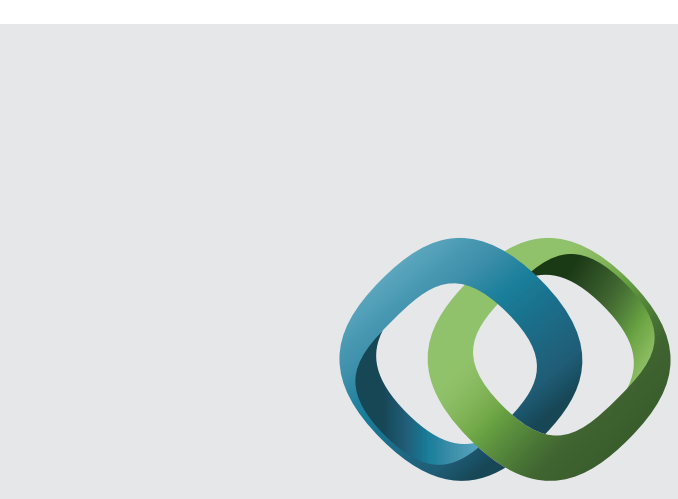

\section{Hindawi}

Submit your manuscripts at

http://www.hindawi.com
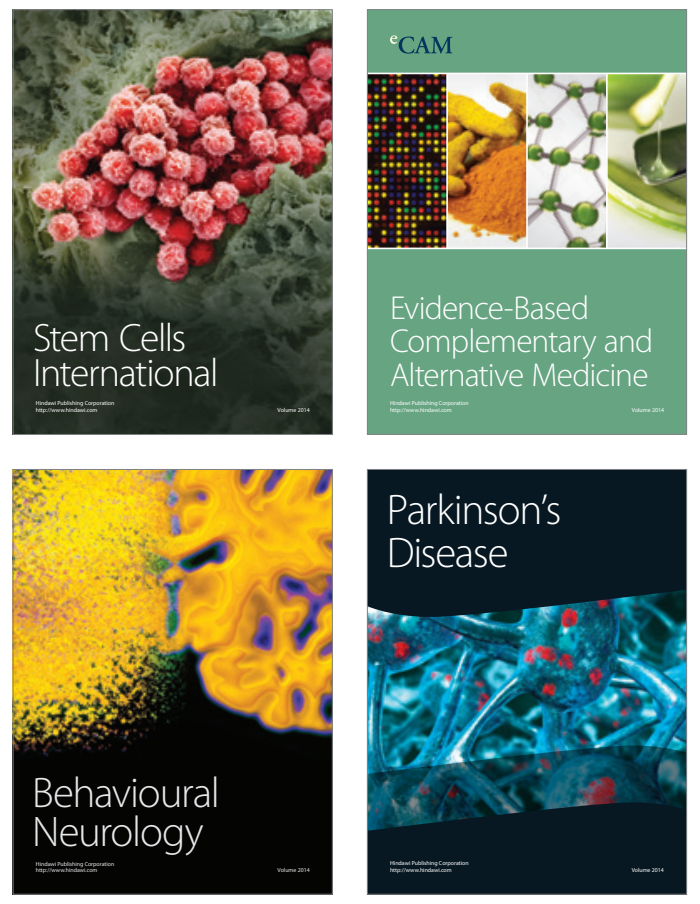
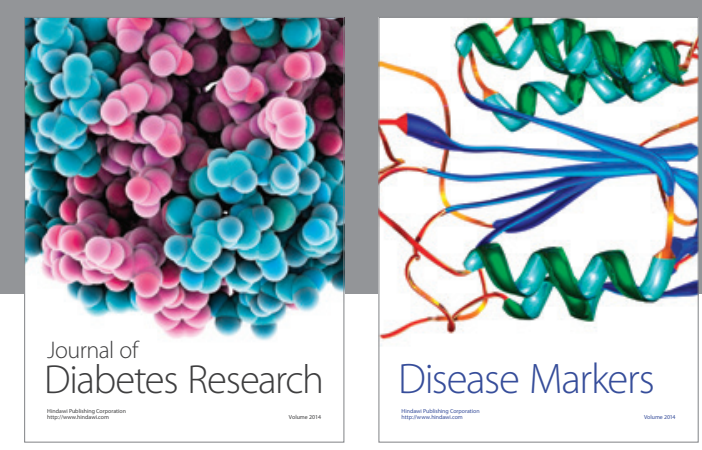

Disease Markers
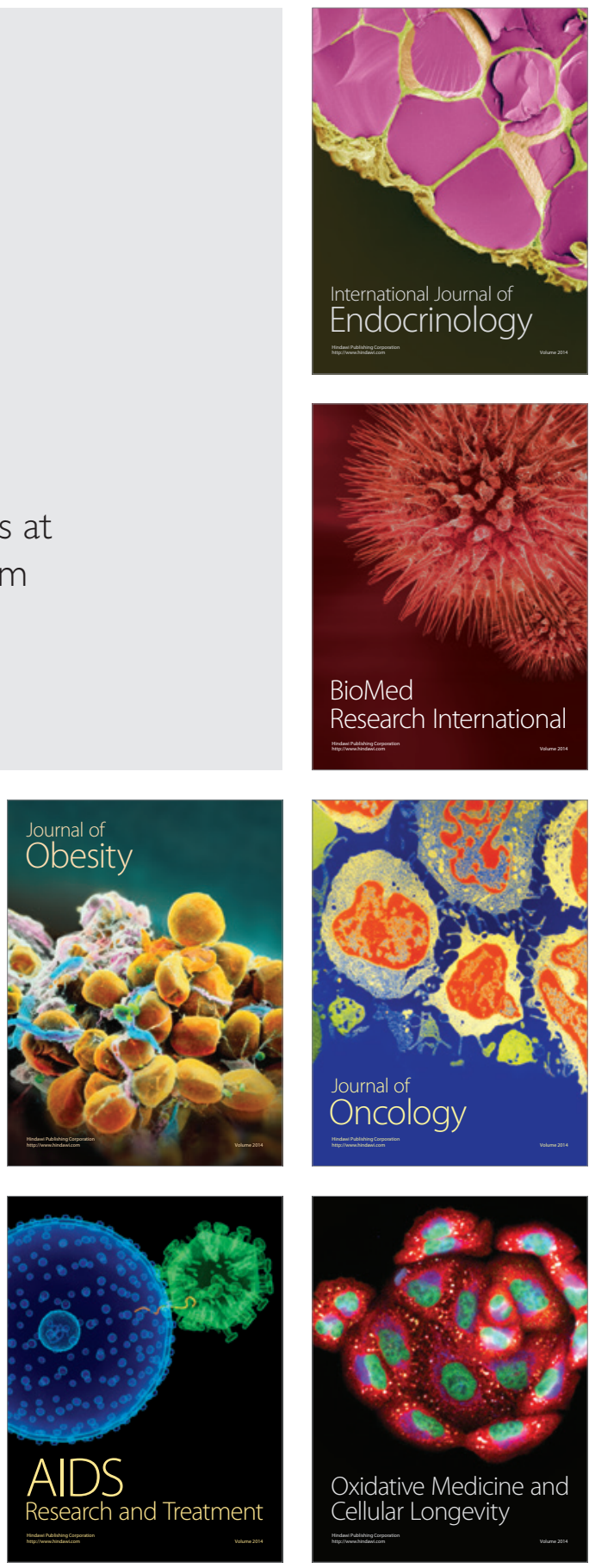